\title{
Cost Effective FBG Based Optical Sensor
}

\author{
UDK 681.586 .5
}

IFAC 4.2 .2

Original scientific paper

Fiber Bragg Grating (FBG) based sensors constitute majority of optical sensors for measuring physical values such as strain, temperature, or both. While properties of FBG alone are well known, interrogation techniques have not been standardized. Most sensors use expensive equipment, such as optical spectrum analyzers, for measuring Bragg wavelength changes as a result of strain, or temperature change. Such method is reliable and gives good results, but cannot be used if we are to construct a cost effective sensor whose use could be widespread. In this paper we demonstrate an alternative way of measuring Bragg wavelength shift that could allow us to build cheap, reliable sensor. Furthermore, the proposed sensor can be thermally stabilized without additional resources. Sensor can, finally, be multiplexed offering quasi-distributed monitoring of smart structures while further reducing the cost.

Key words: fiber Bragg grating, multiplexing, optical sensor, thermal compensation

\section{INTRODUCTION}

Fiber Bragg gratings have been a subject of many research since they were discovered by Hill et al. in 1978 [1]. FBGs are, in short, a piece of optical fiber whose index of refraction periodically varies in the longitudinal direction. As a result, from areas with different refraction indexes, we have small reflections of light. By controlling the change of refraction index we can create structures with great reflectivity on selected wavelengths wavelengths whose reflections interfere constructively.

FBG were initially reserved primarily for academic research. Reasons for that are to be found in fabrications techniques. External writing processing [2] changed that and led to wide acceptance of fiber gratings in communications and, later, in sensor applications. Nowadays, there are couple of techniques for writing refraction index changes, each with some advantages and disadvantages, but all of them give us ability to control the Bragg wavelength - wavelength that has greatest reflection ratio. Reflection, which depends on the grating length and modulation of index of refraction, can almost reach $100 \%$.

As they have some quite remarkable characteristics, FBGs have been used in wide array of applications. They are used in fiber lasers, for wavelength stabilization, as pump reflections, as disper- sion compensators, filters, demuliplexers, OADMs and for gain equalization (see eg. [3, 4]). These applications are connected primarily to field of communications, but FBGs are also extensively used in wide range of sensing applications. They can be used for measuring many physical quantities such as strain, temperature, pressure, ultrasound, acceleration, and high magnetic fields [5]. Best results are obtained in measuring strain and temperature.

\section{FBG SENSOR}

Optical sensors based on FBGs have a number of distinguishing advantages. They can give absolute measurement that is insensitive to power fluctuations of the source, they can be multiplexed using techniques developed for communication purposes, and cost of producing FBGs can be quite low if quantities are high enough.

Typical sensor (Figure 1) uses an optical source with sufficiently broad spectrum, a FBG and a spectrum analyzer. All physical quantities that can be measured affect the central Bragg wavelength of fiber. Change is easily detectable with the optical spectrum analyzer (OSA), under condition that it offers sufficient resolution. All used components are quite cheap except, of course, the spectrum analyzer. Its price heavily affects widespread of use of such sensors and that has motivated us to consider an alternative approach. 


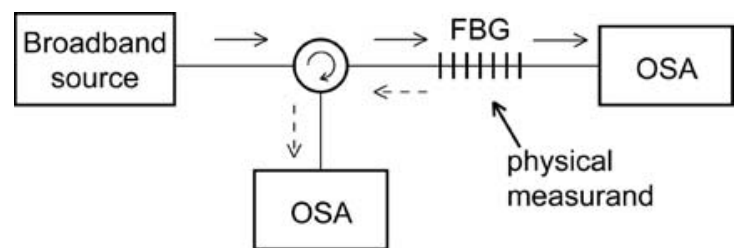

Fig. 1 Typical optical sensor based of FBG. Wavelength shift can be measured on transmission or reflection spectrum of $F B G$

Ideal source for this type of sensor would offer completely linear spectrum in range of interest usually around $4 \mathrm{~nm}$, depending on temperature or strain ranges that we plan to measure. Typical realization has one large drawback - both strain and temperature change the central Bragg wavelength, so if we want to measure only one physical value other must be compensated. Separating these sensitivities can pose quite a problem and can raise cost of the whole system. The simplest method is the one with referent FBG placed in strain-free environment. The referent FBG is then used for temperature measurements, i.e. for compensation of results obtained by the second FBG.

\subsection{Strain and temperature sensitivities}

Before constructing FBG based sensor for measuring strain and temperature, first we have to investigate how FBGs react under these physical quantities. Luckily, behavior of FBGs under these conditions is well known [5]. The wavelength shift, $\Delta \lambda_{B S}$, for an applied longitudinal strain $\varepsilon$ is given by

$$
\Delta \lambda_{B S}=\lambda_{0}\left(1-\rho_{\alpha}\right) \varepsilon,
$$

where $\lambda_{0}$ is the central Bragg wavelength and $\rho_{\alpha}$ is the photoelastic coefficient of the fiber given by

$$
\rho_{\alpha}=\frac{n^{2}}{2}\left[\rho_{12}-v\left(\rho_{11}-\rho_{12}\right)\right] .
$$

In equation (2) $v$ stands for the Poisson's ratio while $\rho_{11}$ and $\rho_{12}$ are components of the fiber strain-optic tensor. Temperature sensitivity, or in other words, change of the Bragg wavelength $\Delta \lambda_{B T}$ for a temperature change of $\Delta T$ is given by

$$
\Delta \lambda_{B T}=\lambda_{0}(1+\xi) \Delta T,
$$

where $\xi$ stands for the fiber thermo-optic coefficient. By combining equations (1) and (3) we end up with following expression

$$
\frac{\Delta \lambda}{\lambda_{0}}=\left(1-\rho_{\alpha}\right) \varepsilon+(1+\xi) \Delta T .
$$

The equation (4) gives us one more useful insight - we can expect greater sensitivity by going to longer wavelengths as $\Delta \lambda$ is proportional to $\lambda_{0}$ (see Table 1). Furthermore, this expression, although exact, is not really useful for quick calculations. An approximate formula for change of the Bragg wavelength in typical fiber is given by

$$
\frac{\Delta \lambda}{\lambda_{0}}=0,78 \times 10^{-6} \varepsilon+8,9 \times 10^{-6} \Delta T .
$$
[5].

Equation (5) matches well to measured results

Table 1 FBG sensitivities at different wavelengths

\begin{tabular}{|c|c|c|}
\hline $\begin{array}{c}\text { Wavelength } \\
(\mu \mathrm{m})\end{array}$ & $\begin{array}{c}\text { Strain sensitivity } \\
\left(\mathrm{pm} \mu \varepsilon^{-1}\right)\end{array}$ & $\begin{array}{c}\text { Temperature sensitivity } \\
\left(\mathrm{pm}{ }^{\circ} \mathrm{C}^{-1}\right)\end{array}$ \\
\hline 0,83 & $\sim 0,64$ & $\sim 6,8$ \\
\hline 1,30 & $\sim 1$ & $\sim 10$ \\
\hline 1,55 & $\sim 1,2$ & $\sim 13$ \\
\hline
\end{tabular}

\subsection{Suggested realization}

Behavior of FBG put under strain or in environment with temperature changes is well known. The only problem that remains is measuring those changes. As we have already pointed out, problem is trivially solved with an optical spectrum analyzer but that raises cost of such a solution. If we are to build a cheap sensor an alternative must be found. We propose a system with two FBGs and two circulators shown in Figure 2.

Two FBGs have to be as similar as possible, which is not such a step requirement as fabrication techniques, especially the phase mask one [5], allow us to make two virtually identical refraction index modulations.

How does the proposed sensor work? If both FBGs are under no strain and under the same temperature, power meter will give us maximum read-

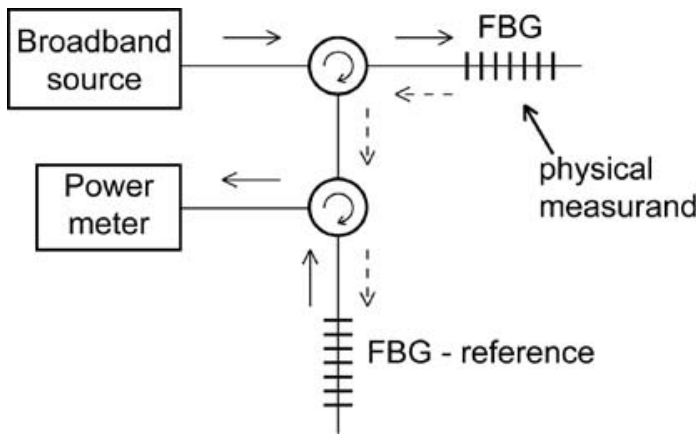

Fig. 2 Optical sensor based on two FBGs 


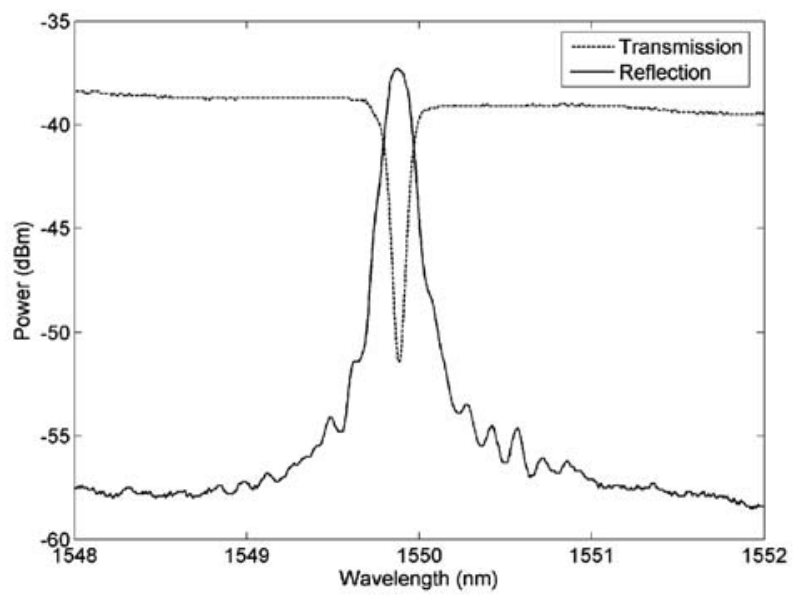

Fig. 3 Measured spectrum of used FBG

ings as reflection spectrums of both gratings overlap. Measured characteristics of used FBGs are given in Figure 3. In case one grating comes under strain or under different temperature compared to the referent FBG, its spectrum will shift toward longer wavelengths and overlapping will decrease, consequently, the power at the power meter will decrease as well.

We used two circulators for separating backward propagating light, but almost the same can be accomplished with two optical couplers. The difference lies in wasted power that takes "wrong" turns at coupler ends. This can be compensated with stronger source, although it can increase cost of the sensor. The biggest shortcoming of the proposed design lies in limited measuring range. FBGs have quite narrow reflection spectrum, so excessive strain can completely separate spectrums of two gratings after which we do not have scaling of power on power meter versus applied strain or temperature change.

\subsection{Temperature compensation}

Use of two almost identical FBGs allows us to easily thermally compensate the whole measurement system. We only have to place two grating close enough so that they are under same temperature. Under that circumstances reflection spectrum of second grating will follow spectrum of the first one that is used for strain sensing and only strain will have effect on reading of power meter. This approach gives best results in rather narrow area as the grating, which is used for amplitude modulation, has quite narrow spectrum. Depending on situation this can be enough - measuring microstrain of around 500 is possible (which, for typical fiber, corresponds to force of around $0.5 \mathrm{~N}$ ). Better precision is obtained with smaller strain changes. Greater forces can be measured by using couple of optical fibers put in parallel without significant price increase. Additional fibers do not need to have gratings imprinted in them. Range for measuring force can easily be broadened with this approach, but the price we need to pay is lowered precision of the measurement system. We can also measure temperature (actually temperature difference) with such a system. It is possible to measure temperature differences of around $50{ }^{\circ} \mathrm{C}$.

Another approach to build sensor based on power meter readings is to use optical filters for amplitude modulation of wavelength shift. In this case we have much greater freedom in choosing the desired optical filter spectrum characteristic, but we loose the ability to easily thermally compensate the sensor. Compensation, in this case, can be done by various already proposed techniques for simultaneous strain and temperature measurement [5].

\section{MULTIPLEXING}

The development of efficient multiplexing techniques enhances the competitiveness of fiber sensors compared with conventional technologies in most application areas. Although implementing multiplexing techniques brings additional problems to solve, it is of fundamental importance if efficient integration of tens or perhaps hundreds of sensors, required for quasi-distributed monitoring of smart structures, will be made.

A range of techniques for the multiplexing of fiber sensors has been developed. The most commonly utilized forms of basic topologies, or network architectures, for implementing multiplexed or fiber sensor arrays include: serial, ladder, star and tree topologies [6]. In addition to these physical fiber wiring diagrams, a method for differentially encoding the sensor signals is required to allow separate sensors in the array to be addressed. These methods include time-, frequency-, code-, wavelength- and polarization-division multiplexing.

For intensity sensor based networks many different multiplexing techniques have been proposed. One of the most straightforward techniques for multiplexing of fiber sensors (and indeed the first passive discrete-sensor network proposed by Nelson et al. [7]) uses time division to address a number of fiber sensors arranged in a network with different time delays from the source and the detector. For such a system, a short-duration pulse of light input to the network produces series of 
distinct pulses at the output. These pulses represent time samples of the sensor outputs interleaved in time sequence. The required duration of the input pulse is determined by the effective differential optical delay $(\tau)$ between the fiber paths to the sensor elements, and repetitive pulsing of the system allows each sensor to be addressed by simple time-selective gating of the detector. Such a system, although straightforward, is not really suited for cost effective system utilizing FBGs.

Wavelength-division multiplexing has been evaluated experimentally for use in fiber communications systems for many years [8]. The technique provides increased channel capacity in communications systems. The use of this technique in sensor application has not received as much practical attention, but it proves to be extremely suitable for fiber Bragg grating based systems.
For constructing the cost effective multiplexed FBG based optical sensor we proposed two solutions. The one depicted in Figure 4 uses same basic components as the single sensor solution, namely circulators, but adds tunable filter for selecting the FBG from which we take measured result in the given moment. Pairs of the FBGs operating at same wavelength have to be placed close enough so that we can presume that they are operating at the same temperature. Thermal stabilization can also be done by using one of the FBGs in the measurement chain as reference, suitable for the case when placing two paired FBGs close enough proves to be problematic. The referent FBG has to be fixed only in one point so no strain influences it. The thermal compensation can be made by premise that two considered effects are linearly independent. The mechanically caused strain $\varepsilon_{m}$ at the mth FBG sensor is given by

Fig. 4 Multiplexing thermally compensated FBG strain sensors using circulators
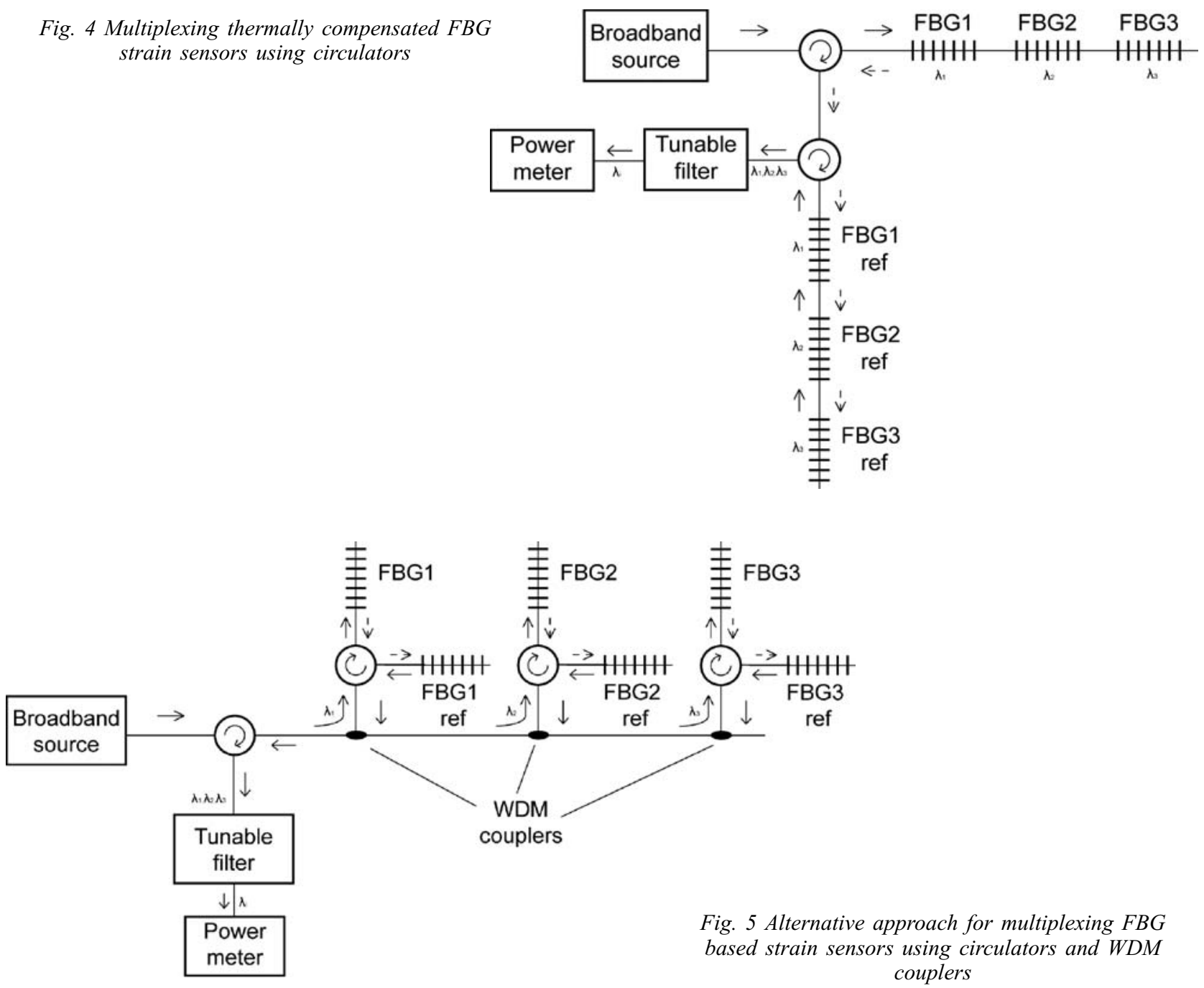


$$
\varepsilon_{m}=\frac{1}{\left(1-\rho_{\alpha}\right)} \cdot\left(\frac{\Delta \lambda_{m}}{\lambda_{0 m}}-\frac{\Delta \lambda_{c}}{\lambda_{0 c}}\right),
$$

where $\Delta \lambda_{m}$ and $\lambda_{0 m}$ stand for the wavelength shift and the central Bragg wavelength of the considered FBG, while $\Delta \lambda_{c}$ and $\lambda_{0 c}$ stand for the FBG used for temperature compensation.

Figure 5 shows a bit different approach that introduces a new component, namely WDM couplers. In this case, placing the pairs of FBGs close enough is easier; so all the FBG pairs can be used for strain measurements.

\section{MEASUREMENTS}

Measurements were done following configuration in Figure 2. As a source we used EXFO tunable laser source (IQ-2600) in ASE regime. In this regime we had almost linear output characteristic in area of interest, but reflected power from single FBG was quite low in the range of $-40 \mathrm{dBm}$. Low power dictated need for a very sensitive detector (Anristu MA9621A was used), but by using stronger, or more concentrated sources (we need sources with approximately $10 \mathrm{~nm}$ spectral width) detection side can be less sensitive and therefore less expensive.

First we measured characteristic of sensor output with spectrum analyzer (EXFO IQ-5240) to better illustrate spectrum characteristics, but we also measured integrated optical power with power meter - which is solution that we propose for a final sensor. As it can be seen in Figures 6 and 7, output spectrum isn't as clean as it would be by

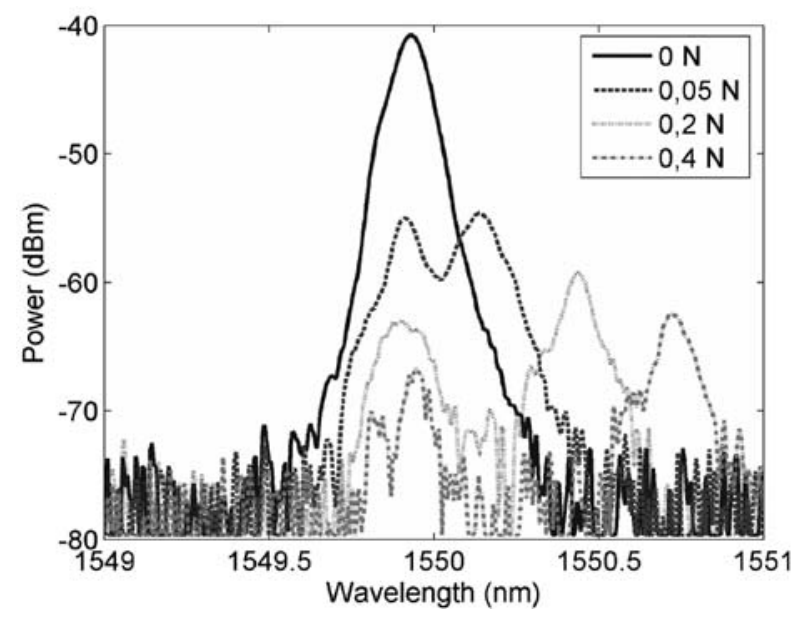

Fig. 6 Changes in output spectrum when one FBG is put under strain

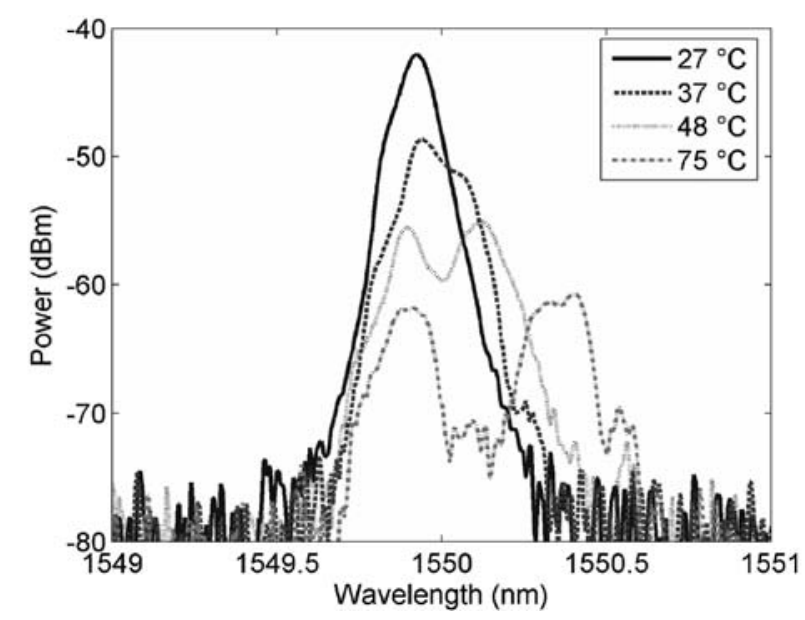

Fig. 7 Changes in output spectrum when one FBG is heated

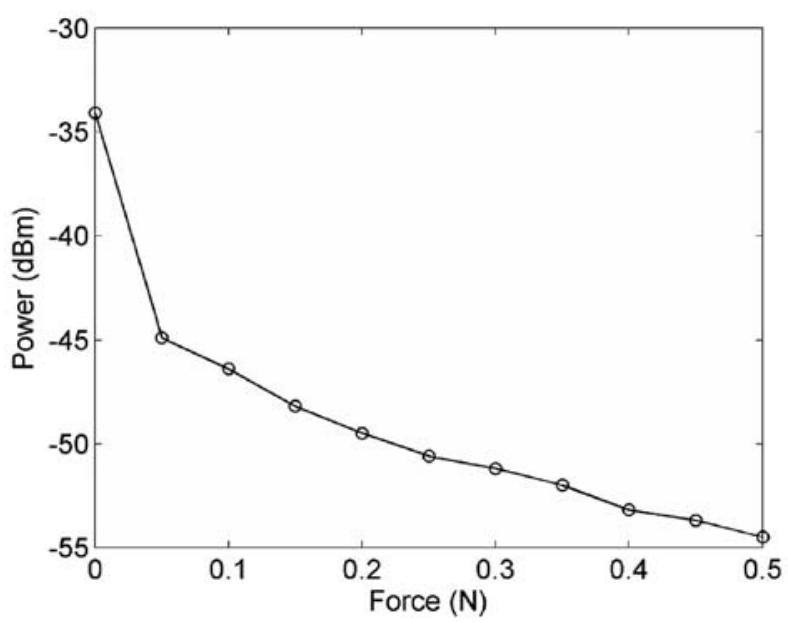

Fig. 8 Integrated power when one FBG is put under strain

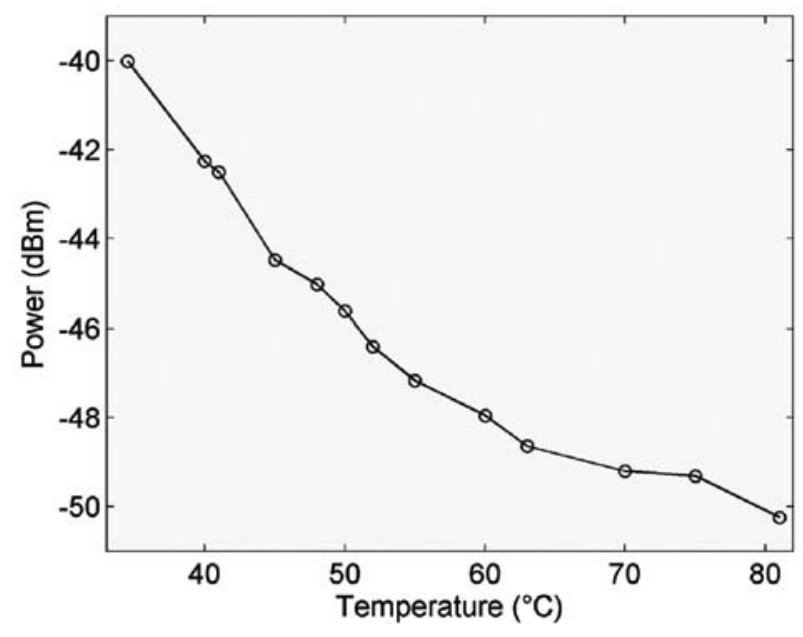

Fig. 9 Integrated power when one FBG is heated 
using a linear filter, but power meter readings show nice correlation between strain or temperature difference applied to two gratings.

Integrated power obtained by power meter when one FBG is put under strain or when it is heated, is given in Figures 8 and 9. These figures demonstrate that we can measure satisfactory range of strain and temperatures. Precision is primarily dictated by stability of power output and precision of power meter, and greater precision can be achieved if Bragg wavelength shift is smaller. The sensitivity to source power fluctuations can be overcome by measuring the difference between source power and the power of the measured reflected signal.

Obtained results show that we can build extremely sensitive sensor if we concentrate on small measuring range. This is more obvious in Figure 8 that shows strain sensitivity, where we can see that power variation is greater than $10 \mathrm{~dB}$ for forces of $0,05 \mathrm{~N}$. The reason for high sensitivity is to be found in use of FBG for power modulation. FBG have extremely sharp edges that give large output power variation as the central Bragg wavelengths start to diverge when strain is applied.

\section{CONCLUSIONS AND DISCUSSION}

The goal of the paper was to demonstrate a cost effective sensor for measuring strain and temperature. In contrast to majority of currently used FBG based sensors that use spectrum analyzers for measuring Bragg wavelength change, we went on different route. As power measurements are the easiest type of measurements in field of fiberoptics, it was logical to develop a low cost sensor using some similar approach. Power modulation with optical filters was already proposed in many books (for instance [5]), but those solutions had problems with temperature stabilization. Our approach offers extremely easy temperature stabilization, but has a limitation regarding measurement range. As this type of sensor should primarily be used for measuring strain, limited range regarding temperature measurements isn't crucial, and measuring greater physical force can be achieved by using many fibers connected in parallel.

An alternative, which is left for future research, can be found in using multimode fibers and slanted multimode fiber Bragg gratings. Their characteristics have also been thoroughly investigated Š10Ć. The main difference between single and multimode Bragg gratings lies in number of dips in transmission spectra. While single mode gratings with constant period of index of refraction have only one dip, multimode equivalents have many and their number depends on excitation conditions. Slanted multimode gratings offer better consistency, as it is easier to stimulate almost all of propagation modes. Multiple dips limit the maximum measuring range as their possible overlapping brings uncertainties in determining wavelength shift from power change. Using results given in paper [10], usable measuring range, before dips from different propagating modes begin to overlap, is somewhere around $40{ }^{\circ} \mathrm{C}$, or microstrain of around 440. Another type of sensor, based on POF ([11]) could be realized, but that is also left for further study. This kind of sensor could prove to be extremely sensitive, but with very limited measuring range.

Finally, we have addressed multiplexing which allows amortization of cost of more expensive components over an array of sensors, reducing the cost of the system per sensor and enhancing the competitiveness of such sensors compared to conventional technologies.

\section{REFERENCES}

[1] K. O. Hill, Y. Fujii, D. C. Johnson, B. S. Kawasaki, Photosensitivity in Optical Fiber Waveguides: Application to Reflection Filter Fabrication. Applyed Physics Letters 32, 647, 1978.

[2] G. Meltz, W. W. Morey, W. H. Glenn, Formation of Bragg Gratings in Optical Fibres by a Transverse Holographic Method. Optics Letters 14 (15), 823 1989.

[3] I. P. Kaminow et. al., Optical Fiber Telecommunications, Volume IIIB. Lucent Technologies, 1997.

[4] J. P. Laude, DWDM - Fundamentals, Components, and Applications. Artec House Publishers, 2002.

[5] K. T. V. Grattan et. al., Optical Fiber Sensor Technology, vol. 2, Devices and Technology. Chapmann \& Hall, 1998.

[6] E. Udd et. al., Fiber Optic Smart Structures. John Wiley \& Sons, 1995.

[7] A. R. Nelson et. al., Passive Multiplexing System for Fiber-Optic Sensors. Appl. Opt., 19, 2917, 1980.

[8] G. Winzer, Wavelength Multiplexing Components A Review of Single-Mode Devices and Their Applications. IEEE J. Lightwave Technol., LT-2, 369-378, 1984.

[9] R. Ramaswami, K. N. Sivarajan, Optical Networks: A Practical Perspective. Morgan Kaufmann Publishers, 2002.

[10] C. Zhao, Z. Li, M. S. Demokan, X. Yang, W. Jin, C. $\mathrm{Lu}$, Studies on Strain and Temperature Characteristics of a Slanted Multimode Fiber Bragg Grating and Its Application in Multiwavelength 
Fiber Raman Ring Laser. Journal of Lightwave Technology, vol. 24. No. 6, June 2006.

[11] Z. Xiong, G. D. Peng, B. Wu, P. L. Chu, Highly
Tunable Bragg Gratings in Single-Mode Polymer Optical Fibers. Photonics Technology Letters, vol. 11, no. 3, March 1999.

Povoljan optički senzor temeljen oko Braggove rešetke. FBG (Fiber Bragg Grating - Braggova rešetka u optičkom vlaknu) temeljeni senzori čine većinu optičkih senzora za mjerenje fizikalnih veličina kao što su naprezanje i temperatura. Dok su svojstva samih rešetaka dobro poznata, tehnike ispitivanja još uvijek nisu standardizirane. Većina senzora koristi skupu opremu, kao što su optički analizatori spektra, za mjerenje promjene centralne Braggove valne duljine radi promjene naprezanja ili temperature. Takva metoda je pouzdana i daje dobre rezultate, no u slučaju povoljnih senzora ne predstavlja optimalan izbor radi visoke cijene ključne komponente - optičkog analizatora spektra. U ovom članku predstavit ćemo alternativan način mjerenja pomaka Braggove valne duljine koji bi mogao omogućiti stvaranje jednostavnog, pouzdanog senzora. Predložena tehnika uz to omogućava termalnu stabilizaciju bez ikakvih dodatnih troškova. Takav senzor moguće je, također, i multipleksirati čime dolazimo do kvazi-distribuiranog nadgledanja naprezanja pametnih struktura.

Ključne riječi: Braggova rešetka, multipleksiranje, optički sensor, termalna kompenzacija

\section{AUTHORS' ADDRESSES}

Tin Komljenović

Marko Bosiljevac

Zvonimir Šipuš

University of Zagreb

Faculty of Electrical Engineering and Computing

Unska 3

HR-10000 Zagreb

Croatia

E-mail: tin.komljenovic@fer.hr 